
Grant \#DE-FG02-91ER20026

\title{
TITLE: CHARACTERIZATION OF DEFECTIVE INTERFERING RNAS ASSOCIATED with RNA PLANT VIRUSES.
}

PIs: T.J. Morris, School of Biological Sciences, University of Nebraska, Lincoln, NE. 68588-0118

A.O. Jackson, Department of Plant Pathology, University of California, Berkeley, California, 94720.

\section{INTRODUCTION}

Our lab was the first to describe and characterize a defective interfering RNA (DI RNAs or DIs) in association with a small RNA plant virus. The features of the DIs that we discovered in infections of tomato bushy stunt virus were compatible with the properties of DIs identified in many animal virus infections. Animal virologists have generally recognized the importance of studying DIs because they are invaluable tools for identifying cis-acting sequences important in virus multiplication and because they offer the opportunity to elucidate mechanisms involved in viral persistence and disease attenuation. Hence our discovery offered a comparably valuable tool for use in plant virus studies for the first time. Since the original observation with TBSV, we discovered the second example of plant viral DI RNAs associated with turnip crinkle virus (TCV), and many other reports have now appeared characterizing DI and DI-like RNAs in other plant viral infections. Our discovery of DIs in plant viruses formed the basis the DOE grant awarded in 1988 which was renewed in 1991. Our previous contributions established plant viral DI RNAs as valuable models for understanding the molecular basis of DI mediated interference and offered the potential for developing novel control strategies for plant disease control. In the renewal, we proposed the following 4 objectives designed to improve our understanding of the mechanisms of DI generation and the precise nature of the RNA sequences necessary for DI replication and encapsidation. In addition, we wanted to address the nature of the DI mediated symptom attenuation and interference effects in plants, and to determine the feasibility of using transgenic plants constitutively expressing DI RNAs for disease control. The progress made on each of these objectives is summarized along with the proposed experiments for the continuation period:

Objective 1. To identify RNA sequences present in the DI RNAs that are important for replication $\&$ encapsidation

This was a very high priority for the grant period. We had previously shown that the TBSV DIs were co-linear deletion mutants consisting of 4 regions of genomic viral RNA sequences derived from the 5'end (region I), the polymerase gene (region II), and two segments of sequence from the $3^{\prime}$ proximal portion of the genome (regions III \& IV). This motif has been established for all of the TBSV DIs that we have isolated and sequenced, and is also consistent with the pattern determined for the DIs of other Tombusviruses studied by our lab as well as by other groups. A diagram of the TBSV genome depicting the derivation of the sequences in the DIs is shown in Fig. 1. We have made significant progress toward defining the essential cis-acting sequences in

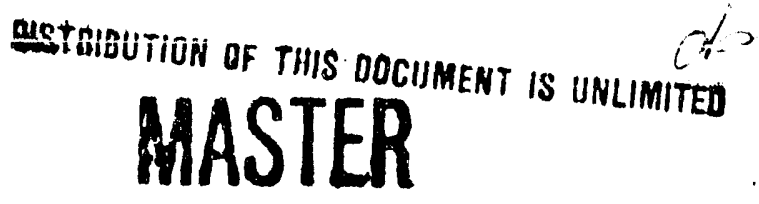


the DI RNAs by systematic mutagenesis of each of the regions in DIs derived from both TBSV and the related cucumber necrosis tombusvirus (CNV). We have shown that regions I, II and IV are necessary for replication while region $\mathrm{III}$ is dispensible. We are also completing a more detailed deletion analysis of region II in which we have identified a hairpin structure that seems to be important in the replicative competency of the DIs. In related studies, we have also developed an encapsidation assay that will permit us to evaluate the encapsidation efficiencies of those mutants that retain replication competency in protoplasts. A manuscript is currently in preparation on these mutagenesis studies. We expect to have completed the functional analysis of the minimal sequences necessary for both replication and encapsidation by the end of the continuation period.

\section{Objective 2. To investigate the mechanisms of de novo generation and evolution of DI RNAs.}

We had established in the previous grant that the DI RNAs appeared to be generated spontaneously from the viral genome during high multiplicity passage of the virus in plant hosts. We have now rigorously confirmed that new DI RNAs are generated de novo from the viral genome. This has been definitively proved using inoculum derived from cDNA clones of two different Tombusviruses, TBSV and CNV. In the latest experiments, we have used PCR to isolate new DI species that appear in plants as early as 7 days after inoculation, and in protoplast infections as early as $48 \mathrm{hr}$ after inoculation. The ability to detect de novo generated DI species in protoplast infections will now permit us to explore the mechanism of origin and selective evolution of the new DI species in greater detail. For example, in previous studies we cloned a progenitor DI species (B10,p4 in Fig. 1) in which the viral sequence between DI regions III \& IV had not yet been deleted. In the continuation period, we will study this specific deletion event in protoplast infections. Mutagenesis in this region should allow us to define the sequence motifs important in this specific RNA recombination event and should provide a good model for understanding the molecular signals that promote sequence deletion.

\section{Objective 3. To elucidate the mechanisms responsible for DI-mediated symptom atienuation} and interference.

We recognized that it would be essential to first elucidate the role of each of the viral genes in the infection process before we could address an understanding of the mechanism of DI based symptom attenuation. We have conducted a systematic deletion analysis of the TBSV genome and determined that the $\mathrm{p} 92$ and an additional small ORF (pX) are the minimal genes needed for independent replication of the genome in protoplasts. We have also refined these studies and constructed artificial defective analogues from the helper virus genome in which we have been able to insert and express reporter genes (CAT and GUS) upon inoculation of plants and protoplasts. This has permitted a detailed study of the invasiveness of the virus in host plants (manuscript accepted in MPMI) as well as a more detailed analysis of the viral genes important in cell-to-cell movement (paper in preparation). Preliminary studies on the utility of DI based foreign gene vectors have also been conducted. These studies are ongoing.

We have also conducted an extensive series of experiments looking at the effect of temperature on virus and DI replication as well as symptom development in both TBSV and CNV. These experiments have involved the construction of chimeric viruses of the two viral genomes. This 
has allowed us to conduct replication competition experiments using DIs and viral helper genomes in homologous and heterologous combinations. These experiments, although still incomplete, show great promise because we have identified some very interesting host specific effects: for example several mutant DI species have been identified that display a host-specific replication deficiency. This will be an important area of emphasis for continued research.

Objective 4. To develop DI RNAs for disease intervention and prophylaxis.

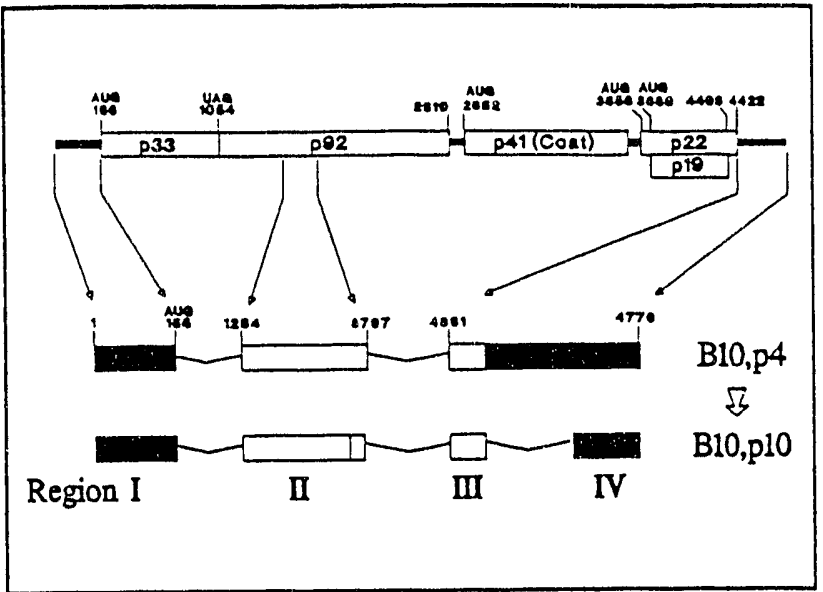

Figure 1: Diagram of the TBSV genome showing the regions of sequence present in several DI RNA species below the genome.

Engineering plants with DI RNA mediated resistance was proposed as a novel approach for interfering with the viral replication process. We constructed $\mathrm{Ti}$ based vectors harboring monomer and dimer constructs of DI sequences, transformed tomato plants and identified transformants harboring DI sequences. We could not ,however, rescue DI related sequences in these plants and could not demonstrate any degree of resistance. This result prompted the reconstruction of DI sequences flanked with ribozyme sequences to permit release of DI transcripts with precise ends upon expression as transcript. These experiments will continue. Recent reports from others reporting resistance in transgenic tobacco to CyRSV mediated by expression of DI transcripts supports the considerable promise of this approach.

Publications for the Grant Period (* reprints or preprints attached)

Scholthof, H.B., Borja, M., Morris, T.J., and Jackson, A.O. 1993. Molecular approaches for control of tomato bushy stunt virus. In: Tomato Molecular Biology, J. Yoder (ed.) Technomic Publ. Co., Lancaster, PA., (in press).

* Scholthof, H.B., Morris, T.J., and Jackson, A.O. 1992. The capsid protein of tumato bushy stunt virus is dispensable for systemic movement and can be replaced for localized expression of foreign genes. Accepted, Molecular Plant Microbe Interactions.

* Knorr, D.A., Mullin, R.H., Hearne, P.Q., and Morris, T.J. 1991. De Novo generation of defective interfering RNAs of tomato bushy stunt virus by high multiplicity passage. Virology 181: 193-202.

* Knorr, D.A. and Morris, T.J. 1990. Origin and evolution of defective interfering RNAs of tomato bushy stunt virus. in Plant Molecular Biology, Ed. R. Herrmann; Plenum.

* Hearne, P., Knorr, D.A., Hillman, B.I., and Morris, T.J. 1990. The complete genome structure and synthesis of infectious RNA from clones of tomato bushy stunt virus. Virology 177: 141-151. 
* Jones, R.W., Jackson, A.O. and Morris, T.J. 1990. Defective interfering RNAs and elevated temperatures inhibit replication of tomato bushy stunt virus in inoculated protoplasts. Virology 176: $539-545$.

* Morris, T.J., and Knorr, D.A. 1990. Defective Interfering RNAs Associated with Plant Virus Infections. in New Aspects of Positive Strand RNA Viruses, Ed. M.A. Brinton \& F. Heinz, Chapter 18, pp. 123-127; ASM Publications, Washington, D.C.

Abstracts \& Presented Papers (1991-92):

(Speaker indicated in bold)

1. David A. Knorr and Thomas J. Morris. (1991). Evolution of defective interfering RNAs of tomato bushy stunt virus during serial passage. ASV.

2. Scholthof, H.B., Chang, Y.C., Petty, I.T.D., Hearne, P.Q., Knorr, D.A., Morris, T.J., and Jackson, A.O. (1991). Comparison of requirements for replication and movement of genomic versus defective interfering RNAs of tomato bushy stunt virus. APS St Louis, Phytopathology 81: 1175.

3. Scholthof, H.B., Morris, T.J., and Jackson, A.O. (1991). Application of defective RNAs expressing a cytotoxic protein for development of resistance against tomato bushy stunt virus. CEPRAP Retreat, Granlibakken, CA

4. Chang, Y-C, H.B. Scholthof, D.A. Knorr, T.J. Morris \& A.O. Jackson, (1992). Molecular characterization of defective interfering RNAs of two Tombusviruses. ASV Comell.

5. Morris, T.J. (1992). Biogenesis of defective interfering RNAs from cloned wild-type and chimeric Tombusviruses. International Satellite Symposium, Cornell University.

6. Hacker, D.L. and Morris, T.J. (1992). Identification of a high-affinity coat protein binding site on satellite RNA D of turnip crinkle virus. ASV Comell.

7. Scholthof, H.B., Morris, T.J., and Jackson, A.O. (1992) Tomato bushy stunt mediated activation of gene expression from defective RNAs. ASV Comell.

8. Law, M.D., Hyslop, J.L. \& Morris, T.J. (1992), Biogenesis of defective interfering RNAs from cloned wild-type and chimeric Tombusviruses. APS, Phytopathology 82: 1113.

9. Scholthof, H.B., Morris, T.J., and Jackson, A.O. (1992). Expression of foreign genes by tomato bushy stunt virus and associated defective RNAs. APS, Phytopathology 82: 1110.

10. Scholthof, H.B. (1992). Molecular approaches for control of tomato bushy virus. Tomato molecular biology symposium. Aug 17-19, UCDavis, CA.

11. Borja, M., Scholthof, H.B., Morris, T.J., and Jackson, A.O. (1992). Progress on the use of defective RNAs to elicit resistance against tomato bushy stunt virus in transgenic plants. CEPRAP Retreat, Oct 16-18, Fallen Leaf Lake, CA. Gicly, likick kict ald

\section{DISCLAIMER}

\footnotetext{
This report was prepared as an account of work sponsored by an agency of the United States Government. Neither the United States Government nor any agency thereof, nor any of their employees, makes any warranty, express or implied, or assumes any legal liability or responsibility for the accuracy, completeness, or usefulness of any information, apparatus, product, or process disclosed, or represents that its use would not infringe privately owned rights. Reference herein to any specific commercial product, process, or service by trade name, trademark manufacturer, or otherwise does not necessarily constitute or imply its endorsement, recommendation, or favoring by the United States Government or any agency thereof. The views and opinions of authors expressed herein do not necessarily state or reflect those of the United States Government or any agency thereuif
} 

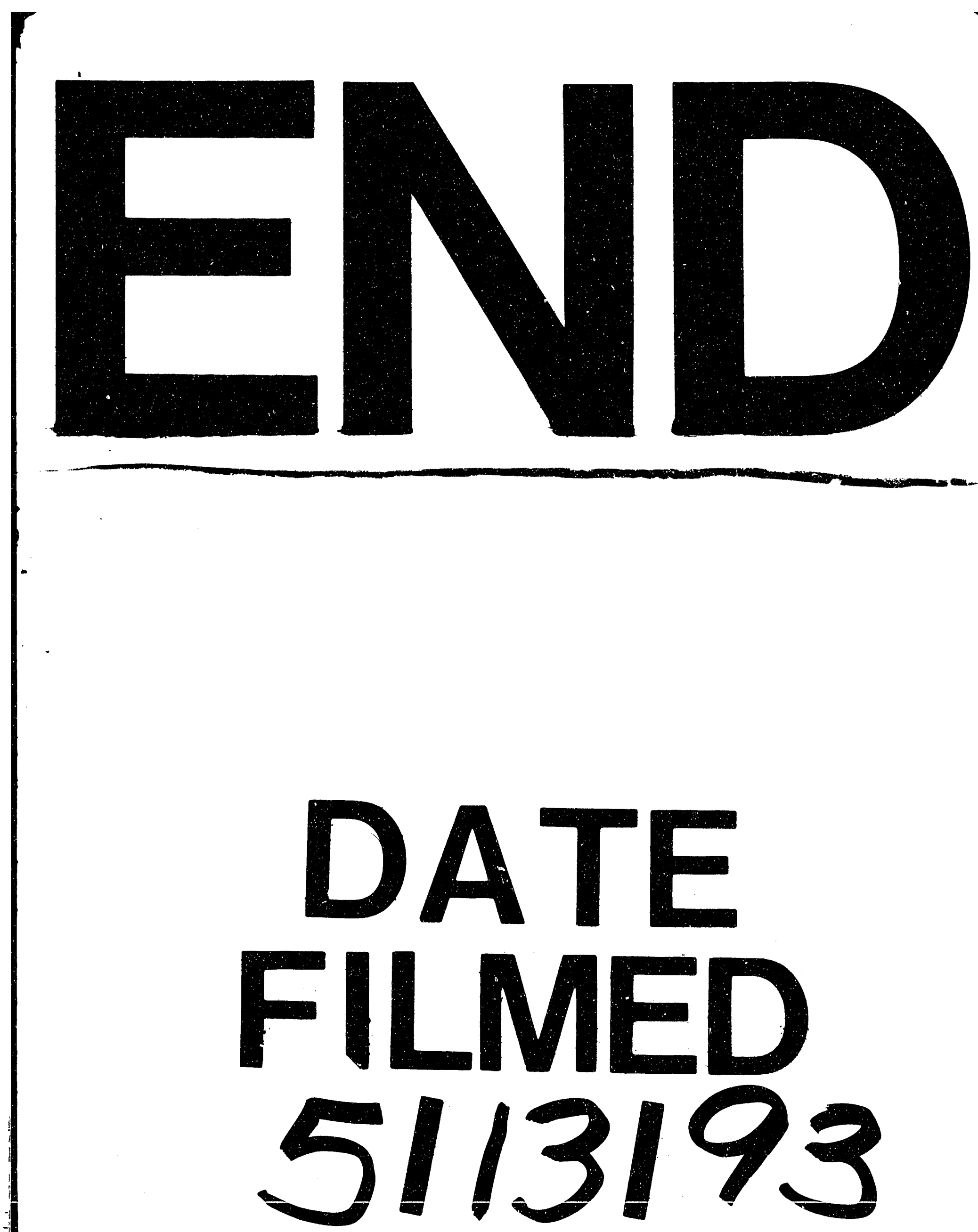


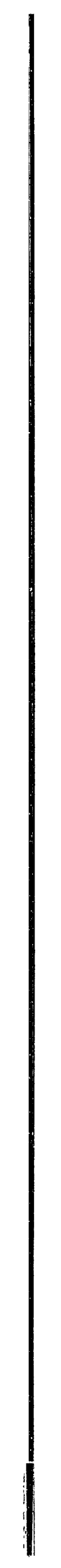

